7. Romanelli AM, Fu J, Herrera ML, Wickes BL. A universal DNA extraction and PCR amplification method for fungal rDNA sequence-based identification. Mycoses. 2014;57:612-22. http://dx.doi.org/10.1111/myc. 12208

8. Samson RA, Yilmaz N, Houbraken J, Spierenburg H, Seifert KA, Peterson SW, et al. Phylogeny and nomenclature of the genus Talaromyces and taxa accommodated in Penicillium subgenus Biverticillium. Stud Mycol. 2011;70:159-83. http://dx.doi.org/ 10.3114/sim.2011.70.04

9. Yilmaz N, Visagie CM, Houbraken J, Frisvad JC, Samson RA. Polyphasic taxonomy of the genus Talaromyces. Stud Mycol. 2014;78:175-341. http://dx.doi.org/10.1016/j.simyco.2014.08.001

10. Lau AF, Drake SK, Calhoun LB, Henderson CM, Zelazny AM. Development of a clinically comprehensive database and a simple procedure for identification of molds from solid media by matrix-assisted laser desorption ionization-time of flight mass spectrometry. J Clin Microbiol. 2013;51:828-34. http://dx.doi.org/ 10.1128/JCM.02852-12

Address for correspondence: Ed Desmond, State Laboratories Division, Hawaii State Department of Health, 2725 Waimano Home Rd, Pearl City, HI 96782, USA; email: edward.desmond@doh.hawaii.gov

\title{
Parathyridaria percutanea and Subcutaneous Phaeohyphomycosis
}

\section{Shivaprakash M. Rudramurthy, ${ }^{1}$ Megha Sharma, ${ }^{1}$ Nandini Sethuraman, Pinaki Dutta, Bansidhar Tarai, Jayanthi Savio, Amanjit Bal, Usha Kalawat, Arunaloke Chakrabarti}

Author affiliations: Postgraduate Institute of Medical Education and Research, Chandigarh, India (S.M. Rudramurthy, M. Sharma, N. Sethuraman, P. Dutta, A. Bal, A. Chakrabarti); Apollo Hospitals, Chennai, India (N. Sethuraman); Max Super Speciality Hospitals, New Delhi, India (B. Tarai); St. Johns Medical College and Research Institute, Bengaluru, India (J. Savio); Sri Venkateshwara Institute of Medical Sciences, Tirupati, India (U. Kalawat)

DOI: https://doi.org/10.3201/eid2509.190383

Parathyridaria percutanea is an emerging fungus causing subcutaneous phaeohyphomycoses in renal transplant recipients in India. We identified $P$. percutanea from a patient with subcutaneous phaeohyphomycosis. From our culture collection, we identified the same fungus from 4 similar patients. We found 5 cases previously described in literature.

${ }^{1}$ These first authors contributed equally to this article.
$P$ arathyridaria percutanea, earlier known as Roussoella percutanea in the order Pleosporales, has been reported to cause subcutaneous phaeohyphomycoses $(1,2)$. P. percutanea belongs to coelomycetes, a group of fungi in which the conidia or asexual propagules lie within a cavity. Parathyridaria spp. generally exist as plant saprobes; $P$. percutanea is the only species reported as an opportunistic pathogen.

We recently observed a case of subcutaneous phaeohyphomycosis caused by $P$. percutanea. The patient was a 33-year-old man who had ACTH-dependent Cushing's disease with 2 cutaneous lesions, one under the left axilla and the other on the ulnar aspect of the left forearm, that had progressed slowly over 3 years (Appendix Figure 1, panel A, https://wwwnc.cdc.gov/EID/article/25/9/19-0383App1.pdf). Direct microscopy of a biopsy sample taken from the left forearm lesion revealed dematiaceous septate hyphae with irregular hyphal swellings (Appendix Figure 1, panel B). Colonies on Sabouraud's dextrose agar at $25^{\circ} \mathrm{C}$ were flat, spreading with sparse aerial hyphae after 1 week, and later turned to cottony greenish-black growth (Appendix Figure 1, panel C). Lactophenol cotton blue mount revealed nonsporulating dematiaceous hyphae with chlamydospores (Appendix Figure 1, panel D). Several attempts to induce sporulation (on oatmeal agar and malt extract agar) failed. Histopathologic examination (Appendix Figure 1, panels E-G) showed neutrophilic infiltration with fungal hyphae, nodular swellings on Giemsa stain, and black hyphae on Grocott-Gomori's methamine silver stain.

We identified the fungus as Roussoella percutanea of the order Pleosporales, later renamed P. percutanea, by PCR sequencing of the internal transcribed spacer (ITS) and $28 \mathrm{~S}$ regions of ribosomal DNA, as described previously (3). ITS sequencing of our strain NCCPF104001 (GenBank accession nos. MG708109 [by ITS] and MG708116 [by 28S]) had 99.8\% identity with CBS128203 (type strain, GenBank accession no. KF322117) and CBS868.95 (GenBank accession no. KF322118), whereas 28S sequences had $100 \%$ identity with CBS128203 (GenBank accession no. KF366448) and CBS868.95 (GenBank accession no. KF366449) (Appendix Figure 2, panels A. B). The patient refused further treatment in the hospital and left against medical advice.

We screened all the isolates deposited in our National Culture Collection of Pathogenic Fungi (NCCPF, Chandigarh) and characterized them phenotypically as Pleosporales. Of 7 such isolates, we identified 4 as $P$. percutanea by sequencing (Table, https://wwwnc.cdc.gov/EID/article/25/9/ 19-0383-T1.htm). We further subjected these isolates to phylogenetic analysis of ITS and large ribosomal subunit (28S) of the rDNA using MEGA software version 6 (https:// megasoftware.net) (3). The strains identified as $P$. percutanea clustered together with the ITS and $28 \mathrm{~S}$ sequences of CBS12608 and CBS868.95 strains, the other 2 P. percutanea 
isolates reported with gene sequences (2). Phylogenetically, Parathyridaria is now a distinct genus and clearly separated from closely related genera such as Roussoella and Thyridaria (Appendix Figure 2, panels A, B).

We searched published literature on Medline and PubMed for subcutaneous phaeohyphomycoses caused by $P$. percutanea or $R$. percutanea and identified 5 cases (Table). All 5 patients originated from tropical countries including the Caribbean islands (5), Republic of the Congo (6), Somalia (7), and India (2,8). Including these 5 with the case-patients we identified from culture and our study patient, 7 of 10 total cases originated in India. The patients had lesions in the extremities; we expect that the fungus is present in our environment and gains access from traumatic inoculation of patients working in the field or walking barefoot. The clinical description of all 10 patients is presented in the Table. Male patients outnumbered female patients. In 2 patients, underlying muscle tendon (2) and joint bursa (7) were involved. No discharging sinus or granuloma formation was seen in any of the 10 patients.

P. percutanea infection occurred in immunosuppressed patients; $9 / 10$ patients were either renal transplant recipients (7 patients) or on steroid therapy (2 patients). The disease manifested 1-3 years posttransplant. Incidence of subcutaneous phaeohyphomycoses is reported in $\leq 3.6 \%$ of renal transplant recipients (10). The tenth patient had diabetes, and the infection of $P$. percutanea occurred at a tattoo site, manifesting 2 years after tattooing. The fungus may remain dormant in subcutaneous tissue after traumatic inoculation and multiply slowly at the opportune time when host immunity is depressed because of immunosuppression or diabetes.

The outcome of $P$. percutanea infection was known in $5 / 10$ patients, and they responded to surgical resection of the lesion followed by voriconazole therapy. The joint guidelines of the European Society of Clinical Microbiology and Infectious Diseases Fungal Infection Study Group and the European Confederation of Medical Mycology on the management of subcutaneous phaeohyphomycosis (9) recommended surgical resection (recommendation AII) along with oral azoles in immunosuppressed patients to prevent dissemination of disease (recommendation BIII). In vitro susceptibility testing, conducted for 3 isolates by Ahmed et al. (2) and Almagro-Molto et al. (7), revealed that $P$. percutanea exhibited low MIC to itraconazole, voriconazole, and posaconazole (Table). Therefore, itraconazole and posaconazole can be used in patients receiving other liver-metabolized drug therapies.

Especially in renal transplant patients in India, P. percutanea could be a possible etiologic agent of subcutaneous phaeohyphomycosis. Sequencing of ITS and 28S regions of ribosomal DNA confirms diagnosis. Effective treatment could include surgical excision of lesions and voriconazole or posaconazole therapy.

\section{About the Author}

Dr. Rudramurthy is a professor at the tertiary care hospital at the Postgraduate Institute of Medical Education and Research, which hosts a World Health Organization collaborating center for reference and research on fungi of medical importance and the National Culture of Pathogenic Fungi, Chandigarh, India. His research interests include antifungal resistance, molecular techniques for diagnosis of fungal infections, and identification and typing of fungi.

\section{References}

1. Tanaka K, Hirayama K, Yonezawa H, Sato G, Toriyabe A, Kudo H, et al. Revision of the Massarineae (Pleosporales, Dothideomycetes). Stud Mycol. 2015;82:75-136. http://dx.doi.org/ 10.1016/j.simyco.2015.10.002

2. Ahmed SA, Stevens DA, van de Sande WWJ, Meis JF, de Hoog GS. Roussoella percutanea, a novel opportunistic pathogen causing subcutaneous mycoses. Med Mycol. 2014;52:689-98. http://dx.doi.org/10.1093/mmy/myu035

3. Shivaprakash MR, Appannanavar SB, Dhaliwal M, Gupta A, Gupta S, Gupta A, et al. Colletotrichum truncatum: an unusual pathogen causing mycotic keratitis and endophthalmitis. J Clin Microbiol. 2011;49:2894-8. http://dx.doi.org/10.1128/ JCM.00151-11

4. Galipothu S, Kalawat U, Ram R, Kishore C, Sridhar AV, Chaudhury A, et al. Cutaneous fungal infection in a renal transplantation patient due to a rare fungus belonging to order Pleosporales. Indian J Med Microbiol. 2015;33:165-7 http://dx.doi.org/10.4103/0255-0857.148435

5. Meis JFGM, Schouten RA, Verweij PE, Dolmans W, Wetzels JFM. Atypical presentation of Madurella mycetomatis mycetoma in a renal transplant patient. Transpl Infect Dis. 2000;2:96-8 http://dx.doi.org/10.1034/j.139-3062.2000.020208.x

6. El Khalfi A, Biau D, Audard V, Heisse C, Paugam A. Phaeohyphomycosis in Roussoella percutanea [in French]. J Mycol Med. 2016;26:e30 http://dx.doi.org/10.1016/j.mycmed.2016.04.065

7. Almagro-Molto M, Haas A, Melcher C, Nam-Apostolopoulos YC, Schubert S. First case of Roussoella percutanea bursitis. Diagn Microbiol Infect Dis. 2017;87:172-4. http://dx.doi.org/10.1016/ j.diagmicrobio.2016.10.021

8. Vasant JA, Maggiani F, Borman AM. Subcutaneous mycotic cyst caused by Roussoella percutanea in a UK renal transplant patient. Mycopathologia. 2017;182:721-5. http://dx.doi.org/10.1007/ s11046-017-0121-0

9. Chowdhary A, Meis JF, Guarro J, de Hoog GS, Kathuria S, Arendrup MC, et al.; European Society of Clinical Microbiology and Infectious Diseases Fungal Infection Study Group; European Confederation of Medical Mycology. ESCMID and ECMM joint clinical guidelines for the diagnosis and management of systemic phaeohyphomycosis: diseases caused by black fungi. Clin Microbiol Infect. 2014;20(Suppl 3):47-75. http://dx.doi.org/ 10.1111/1469-0691.12515

10. Schieffelin JS, Garcia-Diaz JB, Loss GE Jr, Beckman EN, Keller RA, Staffeld-Coit C, et al. Phaeohyphomycosis fungal infections in solid organ transplant recipients: clinical presentation, pathology, and treatment. Transpl Infect Dis. 2014;16:270-8. http://dx.doi.org/10.1111/tid.12197

Address for correspondence: Arunaloke Chakrabarti, Postgraduate Institute of Medical Education and Research, Department of Medical Microbiology, Sector 12, Chandigarh, Union Territory, 160012, India; email: arunaloke@hotmail.com 